TITLE:

Structure of the Hermaphroditic Gonads in a Japanese Cephalocarid Crustacean, Sandersiella sp. with Special Reference to the Oogenetic Mode

AUTHOR(S):

Ando, Hitoshi; Makioka, Toshiki

CITATION:

Ando, Hitoshi ... [et al]. Structure of the Hermaphroditic Gonads in a Japanese

Cephalocarid Crustacean, Sandersiella sp. with Special Reference to the Oogenetic Mode.

PUBLICATIONS OF THE SETO MARINE BIOLOGICAL LABORATORY 2000, 39(1): 35-44

ISSUE DATE:

2000-12-25

URL:

http://hdl.handle.net/2433/176291

RIGHT: 
Publ. Seto Mar. Biol. Lab., 39 (1): 35 - 44, 2000

\title{
Structure of the Hermaphroditic Gonads in a Japanese Cephalocarid Crustacean, Sandersiella sp. with Special Reference to the Oogenetic Mode
}

\author{
HrTOSHI ANDO ${ }^{1)}$ and TosHIKI MAKIOKA ${ }^{2)}$ \\ ${ }^{1)}$ Department of Biochemistry, School of Dental Medicine, Tsurumi University, \\ 2-1-3 Tsurumi, Tsurumi-Ku, Yokohama, Kanagawa 230-8501, Japan \\ ${ }^{2)}$ Institute of Biological Sciences, University of Tsukuba, \\ Tsukuba, Ibaraki 305-8572, Japan
}

\begin{abstract}
Structure of the adult gonads of a hermaphroditic cephalocarid, Sandersiella sp., was examined and some phylogenetic features on the mode of oogenesis were discussed. Both a pair of ovaries and a pair of testes lay along the alimentary canal. A long sac-like ovary was located in each side of the alimentary canal, extended from the eighth to the 18 th and the 19th postcephalic segment. A short oviduct grew forward from the anterior end of each ovary. A pair of short sac-like testes was situated on the dorsal side of the alimentary canal, extended from the seventh to the eleventh postcephalic segment. A short spermiduct arose forward from the anterior end of each testis and then was joined with the oviduct to form a common genital duct opened at the base of the sixth thoracopod. The ovarian wall was a thin single-layered ovarian epithelium. Three and four germaria including several oogonia and very early previtellogenic oocytes embedded in the ovarian epithelium, we rearranged in a line along the ventromedian axis of each ovary. Approximately 10 larger oocytes at various oogenetic stages, previtellogenic and vitellogenic, lay in the ovarian lumen other than the younger oocytes in the germaria. Neither follicle cells nor nurse cells were found about these oocytes. A mature egg oviposited was attached to each gonopod with cement. In the present specimen, the early previtellogenic oocytes should leave the germaria to grow into mature eggs in the ovarian lumen, which a mature egg should be oviposited through each of the oviducts, the common genital ducts, and gonopores. Such an oogenetic egg laying mode is of the typical mandibulate-type, which has been expected in the cephalocarids, one of the most primitive mandibulate arthropods.
\end{abstract}

Key words: Cephalocarida, reproduction, ovary, testis, structure

\section{Introduction}

Two structural and functional types of the ovaries corresponding to the two major arthropod subphyla, the Chelicerata and the Mandibulata, were compared by Makioka (1988) based on various descriptions of arthropod ovaries.

In most chelicerates, the oocytes leave the germarium to grow and to become mature on the outer surface of the tubular ovary. Mature eggs are ovulated into the ovarian lumen through the ovarian wall soon to be transferred into the oviduct. In most mandibulates, however, the oocytes leave the germarium to grow and to become mature in the lumen of the sac-like ovary. Mature eggs are transferred in order into the oviduct. Despite such remarkable differences in structural and oogenetic features of the ovaries between chelicerates and mandibulates, the origin of these differences remains unexplored. In the most primitive chelicerates, such as horseshoe crabs and scorpions, the ovaries are typical 
specimens of the chelicerate-type. In the primitive mandibulates, such as branchiopod crustaceans, however, the ovaries are of the mandibulate-type in anostracans (Criel, 1980; Munuswamy and Subramoniam, 1985; Tommasini and Scanabissi-Sabelli, 1992) and cladocerans (Rossi, 1980; Tommasini and Scanabissi-Sabelli, 1992), but of the remarkably transformed mandibulate-type superficially looking like the chelicerate-type in notostracans (Trentini, 1978; Trentini and Scanabissi-Sabelli, 1978; Ando and Makioka, 1992; Tommasini and Scanabissi-Sabelli, 1992) and conchostracans (Zeni and Zaffagnini, 1989; Tommasini and Scanabissi-Sabelli, 1992). In one of the most primitive crustaceans, the cephalocarid Hutchinsoniella macracantha, an outline of the female reproductive system has been described (Sanders and Hessler, 1970; Hessler et al., 1995), leaving structural and functional details of the ovary behind. In the present study, structural details of the ovary in the hermaphroditic gonad of another cephalocarid, Sandersiella sp. are described and the structural and the oogenetic type of the ovary is discussed.

\section{Materials and Methods}

A specimen of the cephalocarid, Sandersiella sp., was collected from $87 \mathrm{~m}$ deep sandy bottom of the Otsuchi Bay, Iwate, Japan, in October 1995. The body was white and about $2.7 \mathrm{~mm}$ long. A large white egg, about $250 \mu \mathrm{m}$ in diameter and $360 \mu \mathrm{m}$ in length was attached to the most distal segment of each of the ninth rudimental thoracopods with cements. The two eggs were not included in such as the brooding pouch but exposed to sea water.

The whole body was fixed with Bouin's solution, dehydrated and cleared with graduated ethanol-n-butanol series and embedded in paraffin. Serial paraffin sections, $6 \mu \mathrm{m}$ thick, were stained with Mayer's hematoxylin and eosin (H-E), periodic acid-Schiff and Mayer's hematoxylin (PAS-H), or Heidenhain's Azan (Az).

\section{Results}

\section{Hermaphroditic reproductive system}

Sandersiella sp. had both female and male reproductive systems, a pair of ovaries and oviducts and a pair of testes and spermiducts other than a pair of common genital ducts (Fig. 1). A pair of ovaries was located along the both sides of the alimentary canal, extended from the eighth to the 18th (the left ovary) and 19th (the right ovary) trunk segment. A pair of testes was situated on the dorsal side of the alimentary canal and extended from the seventh to the eleventh trunk segment (Fig. 1). A short oviduct, about $100 \mu \mathrm{m}$ long and 10 $\mu \mathrm{m}$ wide, arose forward from the anterior end of each ovary (Fig. 1). A spermiduct, about $70 \mu \mathrm{m}$ long and $8 \mu \mathrm{m}$ wide, extended forward from the anterior end of each testis (Fig. 1). The spermiduct joined with the oviduct at the seventh trunk segment to form a common genital duct, about $150 \mu \mathrm{m}$ long and $12 \mu \mathrm{m}$ wide, connected with the genital pore opened at each base of the sixth thoracopod. Neither seminal receptacles nor seminal vesicles were found on the oviducts or the spermiducts.

\section{Histology of the female organs and female germ cells}

\section{Ovaries and oviducts}

Each ovary was a long straight sac-like organ. The ovarian wall was a single layered thin ovarian epithelium, and each ovarian epithelial cell was flat and contained a basophilic nucleus of about $4 \times 7 \mu \mathrm{m}$ (Figs. 2, 3, 4, and 6). Several oogonia, about $6 \mu \mathrm{m}$ in diameter, 


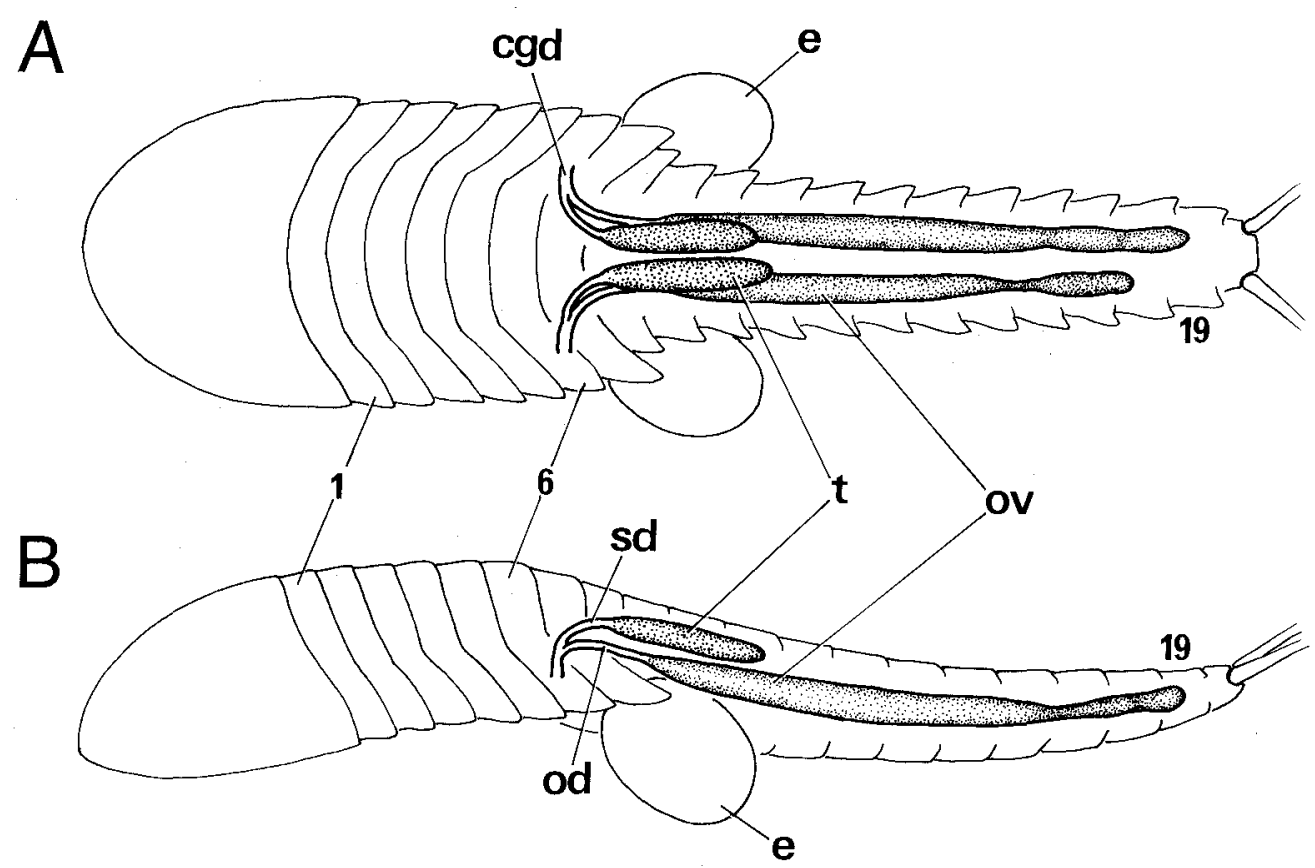

Fig. 1. Schematic drawings of dorsal and sagittal view of the hermaphroditic reproductive system in Sandersiella sp. A pair of long sac-like ovaries is located along both sides of the alimentary canal between the 8th and the 19th trunk segment, and a pair of short sac-like testes above the alimentary canal between the 7th and the 11th trunk segment. A short oviduct is extended forward from the anterior end of each ovary and a short spermiduct from the anterior end of each testis. They are joined each other to form a common genital duct opening at the base of the 6th thoracopod. A pair of mature eggs attached to the 9th thoracopod. A is dorsal and B is sagittal view. Numerals are the number of trunk segments. cgd $=$ common genital duct, $\mathrm{e}=\mathrm{egg}$, od $=$ oviduct, ov $=$ ovary, $s d=$ spermiduct, $\mathrm{t}=$ testis.

and very early previtellogenic oocytes less than $15 \mu \mathrm{m}$ in diameter, and some somatic interstitial cells were loosely aggregated in the central ovarian epithelium to form three (at the 11th, 14th and the 17th trunk segments in the left ovary) and four (at the 10th, 12th, 15th and the 17 th trunk segments in the right ovary) germaria arranged in a line along the ventromedian axis of the ovary (Fig. 2). Larger oocytes, previtellogenic and vitellogenic, were found, not in the ovarian epithelium, but in the ovarian lumen, the larger oocytes much more bulging the ovarian wall. The thin oviductal wall consisted of single-layered flat epithelial cells, the nuclei of which were about $4 \times 6 \mu \mathrm{m}$ (Fig. 7).

Oocytes in the ovary

Seven oocytes, six previtellogenic and a vitellogenic, were found in the left ovary. The smallest previtellogenic oocyte, about $10 \mu \mathrm{m}$ in diameter, was embedded in the ovarian epithelium at the eleventh trunk segment. Two other early previtellogenic oocytes, about 
$15 \mu \mathrm{m}$ in diameter, were attached to their germaria at the 14 th and the 17 th trunk segments. Two others about $40 \times 80 \mu \mathrm{m}$ lay closest to the posterior end of the left ovary in the 18th trunk segment, and the largest previtellogenic oocyte between the 16th and the 18th trunk segments. A vitellogenic oocyte, about $70 \times 450 \mu \mathrm{m}$, most extremely bulging the left ovary between the twelfth and the 15th trunk segments (Fig. 4). In the right ovary, nine oocytes, eight previtellogenic and a vitellogenic, were found. A very early previtellogenic oocyte, about $15 \mu \mathrm{m}$ in diameter, was embedded in the ovarian epithelium at the tenth trunk segment (Fig. 3). All of other oocytes lay in the ovarian lumen. Three others about $20 \times 25 \mu \mathrm{m}$, were attached to their germaria at the twelfth, 15 th, and the 17th trunk segments. Two others about $40 \times 80 \mu \mathrm{m}$ closest to the posterior end of the right ovary were at the 19th trunk segment. A couple of late previtellogenic oocytes, about $50 \times 90 \mu \mathrm{m}$ and $50 \times 120 \mu \mathrm{m}$, were between the 18th and the 19th, and the 16th and the 18th trunk segments. The largest oocytes, in the late vitellogenic, was occupied the ovarian lumen, most extremely bulging the right ovary between the ninth and the 16th trunk segments (Fig 5). In each ovary, all of the oocytes larger than $20 \times 25 \mu \mathrm{m}$ lay in the ovarian lumen, and only the largest oocyte was vitellogenic. The oocytes were arranged in a rule in the ovarian lumen. The oocytes larger than $40 \times 80 \mu \mathrm{m}$, previtellogenic and vitellogenic, were arranged in order of size, the larger ones more anteriorly, nearer the oviduct. Contrarily, the oocytes less than that size were located on the ventral side of the ovarian lumen, between the larger oocytes. They were arranged in reverse, the smaller ones more anteriorly. The oocytes of the boundary size, about $40 \times 80 \mu \mathrm{m}$, were found near the posterior end of the ovary (Fig. 12).

\section{Oogenesis}

The oogonium was spherical cell and included a large and entirely spherical nucleus with some chromatin granules condensed and a nucleolus was not found. The previtellogenic oocytes less than $20 \times 25 \mu \mathrm{m}$ in diameter had a large germinal vesicle, in which no prominent nucleolus was found (Fig. 3), but strong basophilic chromatin granules were agglutinated into several clusters. Their narrow ooplasm was slightly stained with hematoxylin. In the previtellogenic oocytes, about $40 \times 80 \mu \mathrm{m}$, the ooplasm was weakly stained with hematoxylin. Their germinal vesicles, about $30 \mu \mathrm{m}$ in diameter, contained one or two large prominent nucleoli, $10-15 \mu \mathrm{m}$ in diameter, strongly stained with hematoxylin or azocarmine. In the larger previtellogenic oocytes, from $50 \times 90 \mu \mathrm{m}$ to $50 \times 120 \mu \mathrm{m}$, the germinal vesicles were about $30 \mu \mathrm{m}$ in diameter containing a prominent nucleolus of about $18 \mu \mathrm{m}$ in diameter, and their ooplasm was weakly stained with hematoxylin or anilin blue. The vitellogenic oocyte, about $70 \times 450 \mu \mathrm{m}$, had a large germinal vesicles of about $35 \mu \mathrm{m}$ in diameter with a prominent nucleolus about $25 \mu \mathrm{m}$ in diameter, and some yolk granules, 1-5 $\mu \mathrm{m}$ in diameter, stained with eosin, PAS, anilin blue, or azocarmine, were scattered in its ooplasm (Fig. 4). A mature vitellogenic oocyte, about $90 \times 900 \mu \mathrm{m}$, contained a germinal vesicle, about $30 \mu \mathrm{m}$ in diameter, had begun to break down for the maturation division. In the ooplasm, the large yolk granules, 3-5 $\mu \mathrm{m}$ in diameter, stained with eosin, PAS or azocarmine, and the small yolk granules, less than $2 \mu \mathrm{m}$ in diameter, stained with eosin, PAS, or anilin blue, filled their ooplasm (Figs. 5 and 6). Thin vitellin membrane about $2 \mu \mathrm{m}$ thick was found only in the largest vitellogenic oocyte (Fig. 6). No nucleolus was found in its germinal vesicle. Egg membrane was thickened up to about $3 \mu \mathrm{m}$, but egg shell was not formed. Neither follicle cells nor nurse cells were found about all the oocytes. 

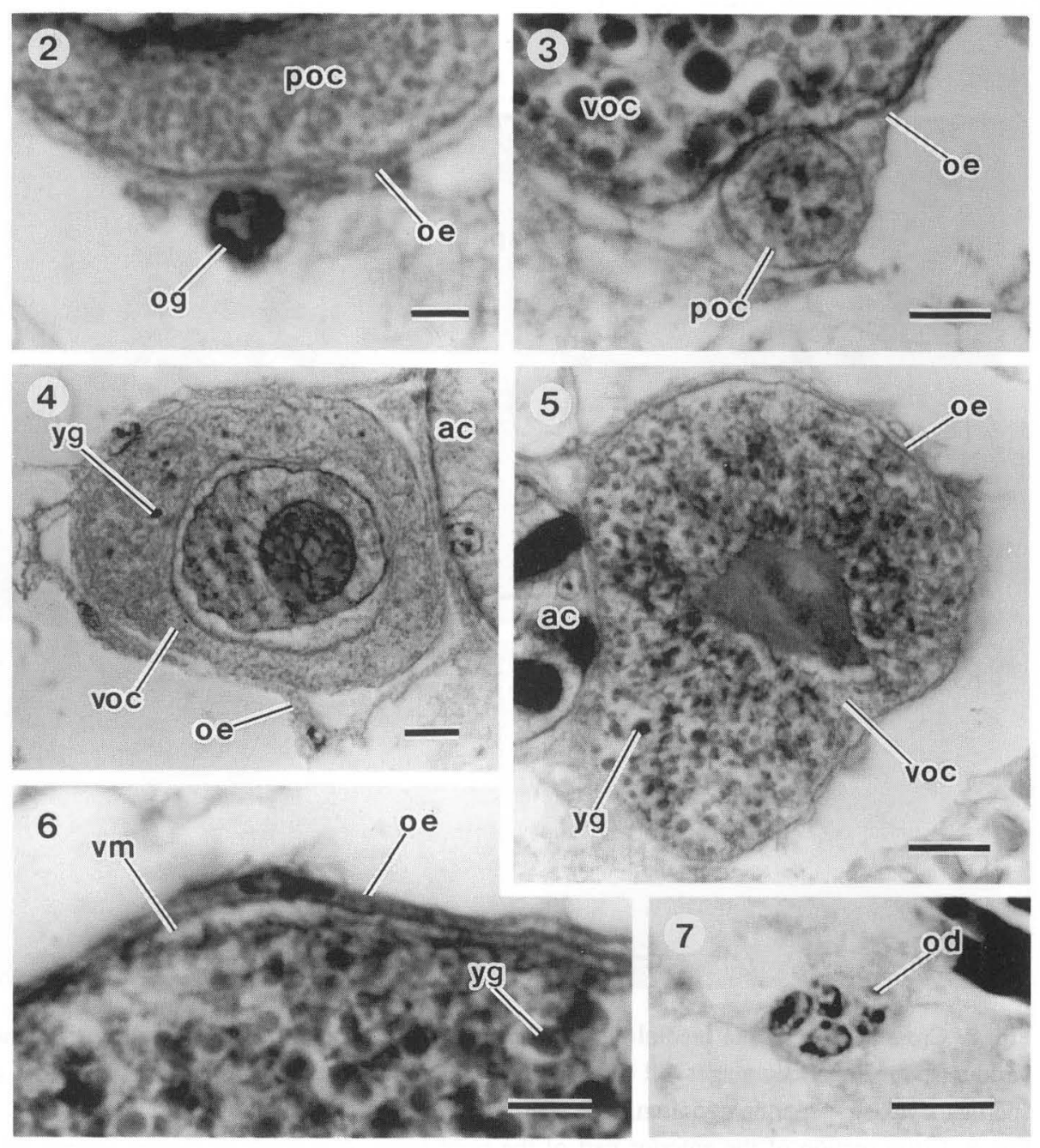

Fig. 2. Cross section of the posterior region of the left ovary. An oogonium lies in the germinal region of the ovarian epithelium running along the ventromedian axis. A previtellogenic oocyte is seen in the ovarian lumen. H-E staining. Scale bar $=5 \mu \mathrm{m}$. oe $=$ ovarian epithelium, og $=$ oogonium, poc $=$ previtellogenic oocyte.

Fig. 3. An early previtellogenic oocyte embedded in the germinal region of the ovarian epithelium and a vitellogenic oocyte in the lumen of the right ovary. PAS-hematoxylin (PAS-H) staining. Scale bar $=10 \mu \mathrm{m}$. voc $=$ vitellogenic oocyte.

Fig. 4. The largest oocyte in the lumen of the left ovary. A large nucleolus is seen in the nucleus. Azan staining. Scale bar $=10 \mu \mathrm{m} . \mathrm{ac}=$ alimentary canal, $\mathrm{yg}=$ yolk granule.

Fig 5. A mature oocyte in the lumen of the right ovary. The germinal vesicle is breaking down. Numerous yolk granules fill the ooplasm. PAS-H staining. Scale bar $=20 \mu \mathrm{m}$.

Fig. 6. Peripheral region of the mature oocyte in the right ovary. A thin vitellin membrane surrounds the oocyte. Numerous yolk granules in various size fill the ooplasm. PAS-H staining. Scale bar $=10 \mu \mathrm{m} . \mathrm{vm}=$ vitellin membrane.

Fig. 7. Cross section of the left oviduct. Some nuclei of the oviductal epithelial cells are seen. H-E staining. Scale bar $=10 \mu \mathrm{m}$. od $=$ oviduct. 

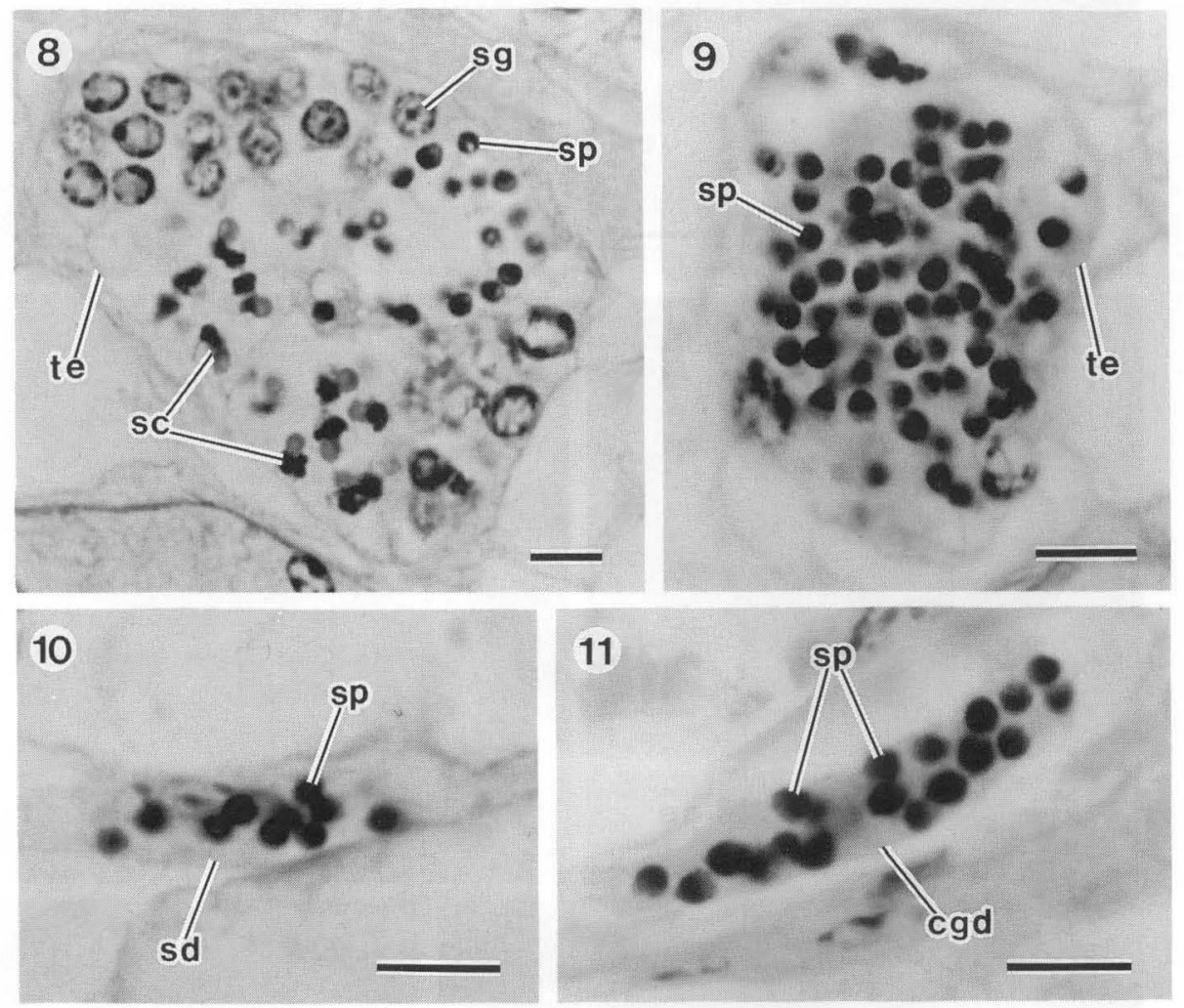

Fig. 8. Cross section of the medial part of the right testis. Some male germ cell cysts showing various spermatogenetic stages fill the testicular lumen. $\mathrm{H}-\mathrm{E}$ staining. Scale bar $=20 \mu \mathrm{m}$. $\mathrm{sc}=$ spermatocyte, $\mathrm{sg}=$ spermatogonium, $\mathrm{sp}=$ sperm, te $=$ testicular epithelium.

Fig. 9. Cross section of the anterior part of the right testis. A number of mature sperms fill the testicular lumen. H-E staining. Scale bar $=10 \mu \mathrm{m}$.

Fig. 10. Cross section of the right spermiduct near the testis. Mature sperms are seen in the spermiductal lumen. H-E staining. Scale bar $=10 \mu \mathrm{m}$. $\mathrm{sd}=$ spermiduct.

Fig. 11. Sagittal section of the left common genital duct. Mature sperms fill the lumen of the common genital duct. $\mathrm{H}-\mathrm{E}$ staining. Scale bar $=10 \mu \mathrm{m}$. cgd $=$ common genital duct.

\section{Histology of the male organs and male germ cells}

Each testis was a short sac-like organ. The testicular wall was a single layered thin testicular epithelium, less than about $4 \mu \mathrm{m}$ thick, and the testicular epithelial cells included a flattened nucleus of about $4 \times 10 \mu \mathrm{m}$ (Figs. 8 and 9). A number of spermatogonia and somatic interstitial cells were aggregated in the testicular epithelium forming some cysts, mainly in the posterior two thirds of each testis. Each spermatogonium, 7-8 $\mu \mathrm{m}$ in diameter, had a large nucleus contained peculiarly agglutinated chromatin granules strongly stained with hematoxylin, and no nucleolus was found. The testicular lumen was occupied with 
numbers of male germ cell-cysts consisting of about 20 to 50 of spermatocytes, spermatids, or mature sperms, which developed synchronously in their cysts (Figs. 8 and 9). The primary and secondary spermatocytes were smaller than the spermatogonia, about 4-7 $\mu \mathrm{m}$ in diameter (Fig. 8). Condensed chromatin particles in their nuclei, less than $4 \mu \mathrm{m}$ in diameter, were strongly basophilic and distinct nucleolus was not formed. Two different regions, the strongly basophilic nuclear region and the weakly basophilic cytoplasmic region, were distinguished (Fig. 8). The mature sperm was aflagellate and slightly flattened, about $2 \mathrm{x}$ $2.5 \mu \mathrm{m}$. In the mature sperm, strongly condensed basophilic nucleus and weakly basophilic cytoplasmic region were distinguished (Figs. 8, 9, 10, and 11). The mature sperms released from the cysts filled the lumens of the spermiducts and also those of the common genital ducts (Figs. 10 and 11). The wall of the spermiduct consisted of single layered thin epithelial cells containing the nuclei about $3 \times 6 \mu \mathrm{m}$. The wall of the common genital duct consisted of single layered elongated epithelial cells and their nuclei were about $3 \times 8 \mu \mathrm{m}$ (Fig. 11).

\section{Discussion}

The Cephalocarida is one of the most primitive crustacean groups (Hessler and Elofsson, 1991; 1992; 1995; Hessler et al., 1995). The representatives have some primitive external morphological features, such as the homonomous body segments, but no internal feature have been examined other than Hutchinsoniella macracantha.

The present species, Sandersiella sp., is hermaphroditic, having both a pair of short sac-like testes with a number of spermatogonia, primary and secondary spermatocytes, spermatids and mature sperms and a pair of long sac-like ovaries with oogonia and previtellogenic and vitellogenic oocytes. Two mature eggs are found to be already oviposited and attached to each of the ninth thoracopods. Paired spermiducts and oviducts are connected with each other into a pair of common genital ducts, which are filled with mature sperms. No seminal receptacles and seminal vesicles are seen in the oviducts and the common genital ducts. Mature eggs pass through the lumen of the oviduct and common genital duct filled with sperms at their oviposition. These structural features of the male and female reproductive systems suggest a self-fertilization, because this system may not be able to avoid a self-fertilization.

In H. macracantha, Sanders and Hessler (1970) and Hessler et al. (1995) described testes and ovaries connected with a pair of common genital ducts through the spermiducts and the oviducts. However, their terminations are somewhat different from those in the present study in particular on the female system. First, they described a pair of "ovaries" as solid tissues located near the maxillary gland. It may correspond to the "germarium" because they have find out oogonia in it despite the oogonia have somewhat unique appearance. Next, an extremely elongated and doubled up "oviduct", in the lumen of which growing oocytes, may correspond to the ovary, in the present study and many other studies on crustacean and other arthropod female reproductive systems. If it is accepted, the both species should share some basic ovarian structural and oogenetic features: such as a pair of branchless long sac-like ovaries and oocytes growing in the ovarian lumen. These are typical features of the mandibulate-type ovaries.

Similar simple sac-like mandibulate-type ovaries have also been found in some other primitive crustaceans, such as in the anostracan branchiopods, Artemia salina (Anderson, 1967), A. fransiscana (Criel, 1980), Chilocephalopsis bundyi and Streptocephalus 


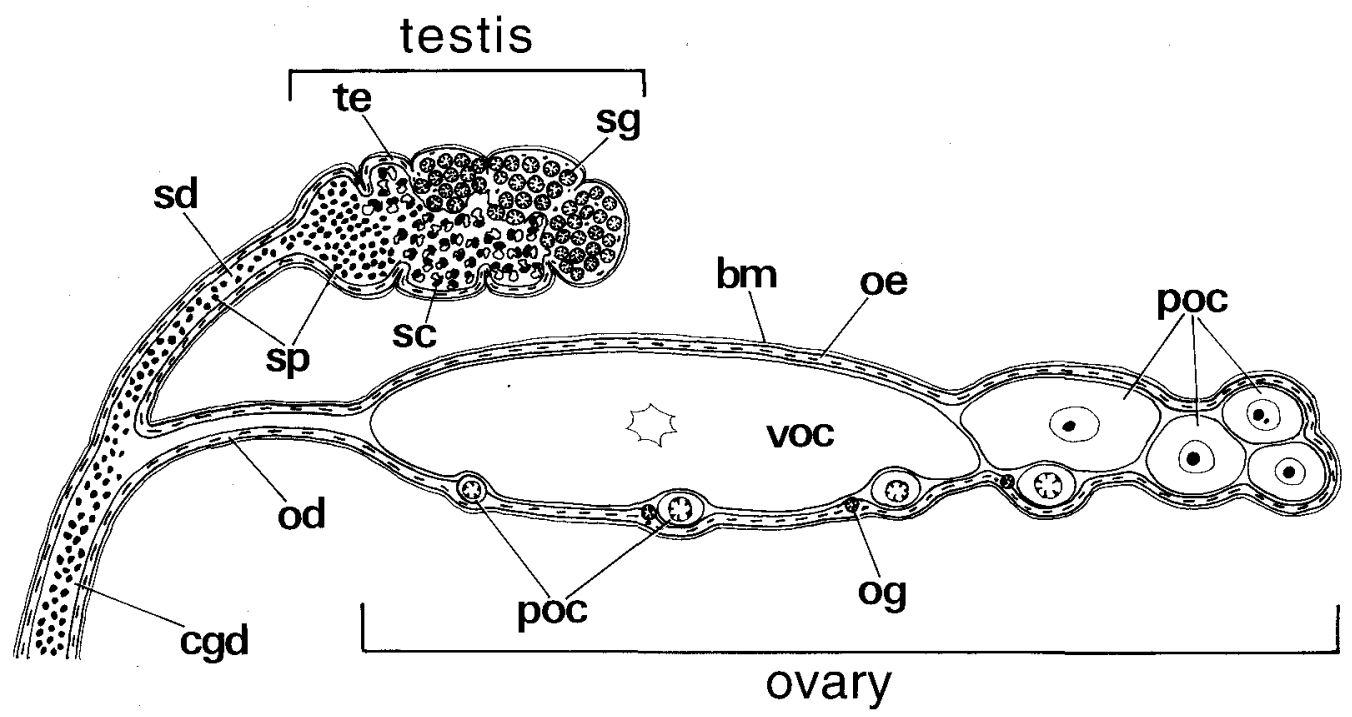

Fig. 12. A schematic drawing of a sagittal section of the hermaphroditic reproductive system of Sandersiella sp., reconstructed from many serial sections. The ovary is a simple sac-like organ consisting of a single layered ovarian epithelium. Several germaria including oogonia and very early previtellogenic oocytes lie along the ventromedian axis of the ovary in the ovarian epithelium. Early previtellogenic oocytes are attached to the ovarian epithelium near the germaria. Some previtellogenic oocytes and a vitellogenic oocyte are located in the ovarian lumen, the latter lying at the nearest to the anterior end of the ovary from which the oviduct arises. The testis is a short sac-like organ. A single layered testicular epithelium is deeply bulged. The spermatogonia and the spermatocytes are seen in the lumen of the cysts in the posterior part of the testis. The mature sperms fill the anterior part of the testis, and also the lumens of the spermiduct and the common genital duct. $\mathrm{bm}=$ basement membrane, $\mathrm{cgd}=$ common genital duct, od = oviduct, $\mathrm{oe}=$ ovarian epithelium, $\mathrm{og}=$ oogonium, poc $=$ previtellogenic oocyte, $\mathrm{sc}=$ spermatocyte, $\mathrm{sd}=$ spermiduct, $\mathrm{sg}=$ spermatogonium, $\mathrm{sp}=$ sperm, te = testicular epithelium, voc = vitellogenic oocyte.

dichotomus (Munuswamy and Subramoniam, 1985) and in the cladoceran branchiopods, Sida crystallina, Daphnia magna, Eurycercus lamellatus, Bythotrephes longimanus and Leptodora kindtii (Rossi, 1980).

On the other hand, some unique ovarian features superficially resembling those in the chelicerate-type ovaries have been described in the notostracan branchiopods, Triops cancriformis (Longhurst, 1955; Trentini, 1978; Trentini and Scanabissi-Sabelli, 1978; Tommasini and Scanabissi-Sabelli, 1992), T. longicaudatus (Ando and Makioka, 1992) and Lepidulus apus (Longhurst, 1955), and the conchostracan branchiopods, Limnadia lenticularis (Zaffagnini and Minelli, 1970) and Leptestheria dahalacensis (Zeni and 
Zaffagnini; 1989). Tommasini and Scanabissi-Sabelli (1992) distinguished these two different ovarian structural features among the branchiopods, but they did not tell which is more primitive because they could not compare these features with any archetype. The present study offered the cephalocarid ovarian structural features to be of the typical mandibulate-type as an archetype, which supports the primitiveness of the mandibulate-type in ovarian structural features among crustacean and therefore makes it possible to consider that the typical mandibulate-type, as it is in ovarian structural features of the anostracans and cladocerans, should be primitive and that the ovarian structural features of the notostracans and conchostracans superficially resembling those in the chelicerate-type should be derived from those of the mandibulate-type.

The remipedians, also known to be hermaphroditic, are considered either as another most primitive crustacean group or as closely related to the copepods (Yager, 1991; Schram, 1986; Ito and Schram, 1988). The remipedian ovaries were described in Speleonectes benjamini, Godzillogonomus frondosus (Yager, 1991) and Lasionectes entrichoma (Ito and Schram, 1988). Some common features of the remipedian ovaries, such as paired sac-like ovaries with the germarium at each anterior end and oocytes growing in the ovarian lumen, show that these features should also be of a typical mandibulate-type.

The most primitive form of the crustacean ovary should be of a simple sac-like one including growing oocytes in its lumen as found in the cephalocarids and remipedians, and all the diverged ovaries in other crustacean groups might have been derived from the primitive form. Moreover, the crustacean phylogenetic position in the arthropods suggests that the primitive form is closest not only to the archetype of the crustaceans, but also to that of the mandibulates.

\section{Acknowledgments}

We thank Dr. Ichiro Takeuchi, Otsuchi Marine Research Center, Ocean Research Institute, University of Tokyo, Dr. Rei Ueshima, University of Tokyo, and Prof. Yoshihisa Shirayama, Seto Marine Biological Laboratory, Graduate School of Science, Kyoto University, for their kind assistance in collecting the specimen. We also thank Dr. Katsumi Miyazaki, Seto Marine Biological Laboratory, Graduate School of Science, Kyoto University, for his helpful advice and encouragements.

\section{References}

Anderson, D. T. 1967. Larval development and segment formation in the branchiopod crustaceans Limnadia stanleyana King (Conchostraca) and Artemia salina (L.) (Anostraca). Australian Journal of Zoology, 15, 47-91.

Ando, H. and Makioka, T. 1992. Notes on structure of the ovary and oogenesis in Triops longicaudatus (Notostraca, Branchiopoda, Crustacea). Proceedings of Arthropodan Society of Embryological Society of Japan, 27, 1-4.

Blades-Eckelbarger, P. I. and Youngbluth, M. J. 1984. The ultrastructure of oogenesis and yolk formation in Labidocera aestiva (Copepoda: Calanoida). Journal of Morphology, 179, 33-46.

Criel, G. 1980. Morphology of the female genital apparatus of Artemia. In, Persoone, G., Sorgoloos, P., Roels, O. and Jaspers, E. (eds.) The Brine Shrimp Artemia. Vol. I. Morphology, Genetics, Radiobiology, Toxicology, pp. 75-86.

Hessler, R. R. and Elofsson, R. 1991. Excretory system of Hutchinsoniella macracantha (Cephalocarida). Journal of Crustacean Biology, 11, 356-367. 
Hessler, R. R. and Elofsson, R. 1992. Cephalocarida. In, Harrison, F. W. and Humes, A. G. (eds.) Microscopic Anatomy of Invertebrates. Vol. 9, Crustacea. Wiley-Liss, New York, pp. 9-24.

Hessler, R. R. and Elofsson, R. 1995. Segmental podocytic excretory glandsin the thorax of Hutchinsoniella macracantha (Cephalocarida). Journal of Crustacean Biology, 15, 61-69.

Hessler, R. R., Elofsson, R, and Hessler, A. Y. 1995. Reproductive system of Hutchinsoniella macracantha (Cephalocarida). Journal of Crustacean Biology, 15, 493-522.

Ito, T. and Schram, F. R. 1988. Gonopores and the reproductive system of nectiopodan Remipedia Lasionectes entrichoma. Journal of Crustacean Biology, 8, 250-253.

Longhurst, A. R. 1955. The reproduction and cytology of the Notostraca (Crustacea, Phyllopoda). Proceedings of Zoological Society of London, 125, 671-680.

Makioka, T. 1988. Ovarian structure and oogenesis in Chelicerates and other Arthropods. Proceedings of Arthropodan Society of Embryological Society of Japan, 23, 1-10.

Munuswamy, N. and Subramoniam, T. 1985. Oogenesis and shell gland activity in a freshwater fairy shrimp Streptocephalus dichotomus Baird (Crustacea: Anostraca). Cytobiosis, 44, 137-147.

Rossi, F. 1980. Comparative observations on the female reproductive system and parthenogenetic oogenesis in Cladocera. Bollettino di Zoologica, 47, 21-38.

Sanders, H. L. and Hessler, R. R. 1970. Reproductive system of Hutchinsoniella macracantha. Science, $168,1464-1465$.

Schram, R. 1986. Crustacea. Oxford University Press, New York, 606 pp.

Tommasini, S. and Scanabissi-Sabelli, F. 1992. Morphological and functional aspects of the female gonad of the conchostracan Leptestheria dahalacensis (Rüppel 1837) (Crustacea, Branchiopoda), and a comparison with the gonads of other Branchiopoda. Canadian Journal of Zoology, 70, 511-517.

Trentini, M. 1978. Osservazioni sull'ovogenesidi Triops cancriformis (Phyllopoda, Notostraca). Rendiconti della Accademia Nazionale dei Lincei. Classe di Scienze Morali, striche e filologiche, Ser. 8, 90-93.

Trentini, M. and Scanabissi-Sabelli, F. 1978. Ultrastructure and egg shell formation in Triops cancriformis (Crustacea, Notostraca). I. Origin and differentiation of nurse cell. Cell and Tissue Research, 194, 71-77.

Yager, J. 1991. The reproductive biology of two species of Remipedia. In, Bauer, R. T. and Martin, J. W. (eds.) Crustacean Sexual Biology. Colombia University Press, New York, pp. 271-289.

Zaffagnini, F. and Minelli, G. 1970. Origine e natura delle memblane che avologono l'vovo di Limnadia lenticularis. Bollettino di Zoologica, 37, 139-149.

Zeni, C. and Zaffagnini, F. 1989. Electron microscopic study on oocytes, nurse cells and yolk formation in Leptestheria dahalacensis (Crustacea, Conchostraca). Invertebrate Reproduction and Development, 15 , 119-129. 


\section{Instruction to Authors}

The Publications of the Seto Marine Biological Laboratory (referred as the Publications hereafter) are issued regularly by the Seto Marine Biological Laboratory of Kyoto University. The publications aim to contribute to the progress of marine biology and related sciences by publishing the scientific papers regarding organisms of mainly Japanese and Indo-Pacific waters. Papers related to the natural history, such as taxonomy, morphology, and evolutionary biology are the most suitable, and particularly those recording works done at the Laboratory are favorable.

Submitted papers must not have been published nor be under consideration for publishing elsewhere in any languages. The submitted papers will be reviewed at least by two referees, and only those papers evaluated their scientific findings are worth for publication will be accepted. Such papers that is judged not paid sufficient attention to the wildlife conservation and the humane treatment of animals will be rejected.

Manuscript should be sent to the editor in chief (Yoshihisa Shirayama) of the Publications at the following address:

Seto Marine Biological Laboratory,

459 Shirahama, Wakayama Pref., 649-2211, Japan

Authors are requested to read the following instruction carefully, and prepare their manuscript properly. Poor attention to the instruction may cause unnecessary delay of the processing of papers.

Manuscripts should be prepared in English as concisely as possible. Those authors whose native language is not English should ask native English speaker to correct language usage before submitting the manuscript. Original and two copies of the manuscript consisting of text, tables and the illustrations should be provided.

\section{Text:}

The text should be printed in double spaced manner on one side of A4 size paper leaving margins of more than $3 \mathrm{~cm}$ in width all around. All sheets should be numbered consecutively, and the name of the senior author should be given on the upper right corner.

The first page of the text should include the title of the paper, information of author(s) (name, affiliation, and corresponding address inclusive of e-mail address of all authors and telephone and fax numbers of the representative author), the running title (not more than 50 characters), and key words (not more than 10 items).

The second page should include only the abstract of the paper (less than 300 words), expressing concisely the hypothesis, the approach the author(s) adopted, the results, and the conclusion.

The main body of the text consisting of introduction, materials and methods, results, discussion, acknowledgments, reference and so on, should be prepared from page 3 . The papers listed in the reference section should be referred as Tokioka $(1960,1961$ ) $)$ or (Harada, 1995; Harada et al., 1992; Harada and Fuse, 1994).

The reference should list all the papers mentioned in the text alphabetically in the following manner.

Referring papers published in journals:

Shirayama, Y. 1984a. The abundance of deep-sea meiobenthos in the Western Pacific in relation to environmental factors. Oceanologica Acta, 7, 113-121.

Shirayama, Y. 1984b. Vertical distribution of meiobenthos in the sediment profile in bathyal, abyssal and hadal deep-sea systems of the Western Pacific. Oceanologica Acta, 7, 123-129.

Shirayama, Y. and Horikoshi, M. 1989. Comparison of the benthic size structure between sublittoral, 
upper-slope and deep seas of the Western Pacific. Internationale Revue der gesamten Hydrobiologie, $74,1-13$.

(It should be noticed that the title of journals should not be abbreviated.)

Referring papers published in books:

Shirayama, Y. 1995. Current status of deep-sea biology in relation to the $\mathrm{CO}_{2}$ disposal. In, Handa, N. and Ohsumi, T. (eds.) Direct Ocean Disposal of Carbon Dioxide, Terra Scientific Publishing Company, Tokyo, pp. 253-264.

Referring a book as a whole:

Gage, J. D. and Tyler, P. A. 1991. Deep-Sea Biology. Cambridge University Press, Cambridge, 504 pp.

\section{Tables:}

The tables should be provided in the shape ready to reproduce. Each table should be printed on a separate sheet of paper using a font "Times new roman" or related one. The large table that can not be printed in 2 pages is not acceptable.

\section{Figures:}

Illustrations should be prepared in a size of not smaller than B5 and not larger than A3. They should fit to the shape of the page, that is $14 \mathrm{~cm}$ wide by $20 \mathrm{~cm}$ height at maximum. Authors are requested to pay the most careful attention to the thickness of lines, the size of letters and the spacing of drawings. Photographs should be printed in a high contrast tone. Manuscripts inclusive of figures will not be returned to the authors unless they requested. The cost for printing the color plates must be covered by the author.

\section{Proofs:}

The first galley proof will be sent to the senior author. The author should return it to the editor within 3 days after the receipt. Only corrections of typographic errors are allowed at this stage.

\section{Reprints:}

The publications provide 50 reprints to the senior author free of charge. The author can order additional reprints when the author returns the galley proof to the editor.

\section{Page charge:}

The publications do not set the maximal length of each article, and will not bill the page charge for the regular black-ink printing. However, the cost for printing color plates should be covered by the author(s).

\section{Computer files:}

To save the cost for publishing and to reduce typographic errors, the publications request the author to provide computer files to the editorial board when the manuscript is accepted for publishing. Use of the 3.5 inch $2 \mathrm{DD}$ or $2 \mathrm{HD}$ floppy disk (preferably formatted by MS-DOS) that records plain text files and clearly marked the author name and the title of the paper is requested. Use of electric mail may be also acceptable. If the author used a word processor for preparing the manuscript, the binary file used by the program is also requested to be provided, and information for the word processor program must be provided. It is not recommended to provide data files in stead of line drawings and photographs. 